\title{
The Breast Feeding Adaptation Scale-Short Form: Development and Testing of Its Psychometric Properties and Measurement Invariance
}

\author{
Sun-Hee Kim \\ Associate Professor, College of Nursing · Research Institute of Nursing Science, Daegu Catholic University, Daegu, Korea
}

Purpose: This study sought to develop the Breastfeeding Adaptation Scale-Short Form (BFAS-SF) for use at 4 weeks postpartum, to test its validity and reliability, and to examine its measurement invariance. The latent mean score of the BFAS-SF across multiple groups was also compared. Methods: This methodological research study was conducted to develop a short form of the BFAS and to test its psychometric properties and measurement invariance. Data were collected twice for measurement invariance testing. The sample included 431 and 272 breastfeeding mothers at 2 weeks and 4 weeks postpartum, respectively. Results: Confirmatory factor analysis supported six dimensions of the BFAS-SF at 4 weeks postpartum. Multi-group confirmatory factor analysis revealed evidence for invariance of the BFAS-SF according to employment status, parity, delivery mode, and the postpartum period. There were statistically significant latent mean differences. Mothers who were unemployed and who had a vaginal delivery showed significantly higher scores for breastfeeding confidence, sufficient breast milk, and baby's satisfaction with breastfeeding. Conclusion: The BFAS-SF is valid, reliable, and an appropriate instrument for assessing mothers' breastfeeding adaptation. It can be used to compare mean scores according to employment status and delivery mode.

Key words: Breast feeding; Mothers; Physiological adaptation; Psychological adaptation; Reproducibility of results

\section{Corresponding author Sun-Hee Kim \\ https://orcid.org/0000-0001-8518-5670}

College of Nursing, Daegu Catholic University,

33 Duryugongwon-ro, 17-gil, Nam-gu, Daegu 42472, Korea

TEL +82-53-650-4831 FAX +82-53-650-4392

E-MAIL sunhee421@cu.ac.kr

*This work was supported by research grants from Daegu Catholic University in 2017 (20171135).

Received May 25, 2019 Revised Jun 24, 2019 Accepted Jul 4, 2019 (a) This is an Open Access article distributed under the terms of the Creative Commons Attribution NonCommercial License (http://creativecommons.org/licenses/by-nc/4.0/) which permits unrestricted noncommercial use, distribution, and reproduction in any medium, provided the original work is properly cited.

\section{INTRODUCTION}

\section{Need for Study}

New mothers in Korea convalesce and adapt to motherhood for roughly 4.6 weeks at a combination of postpartum care centers $(75.1 \%)$, their own homes $(70.2 \%)$, their parents' homes (19.8\%), or their in-laws' homes (2.4\%) after being discharged from the hospital 3 5 days post-childbirth [1]. As new mothers receive professional postpartum services in the hospital for only a short time period, it is important for them to be able to assess their own adaptation to breastfeeding after being discharged, in order to detect any early problems and to find solutions with the help of professionals or other resources. The Breastfeeding Adaptation Scale (BFAS) was developed in 2009 for new mothers to self-evaluate their adaptation to breastfeeding [2]; numerous findings evaluating the BFAS have since been reported in nursing studies conducted in Korea [3-7].

The BFAS was developed by defining the concept of adaptation to breastfeeding based on Roy's four modes of adapta- 
tion through a review of the literature on breastfeeding, existing tools for assessing breastfeeding, and an analysis of interviews with breastfeeding mothers and clinical nurses [2]. During development, the content validity, construct validity, and the internal consistency reliability of the BFAS were verified. As the construct validity of the scale was verified through exploratory factor analysis and known-group validity during development, the validity of the factors should be reexamined through confirmatory factor analysis. The validity of the scale is subject to change according to time and culture, making a continued validation process necessary. Over the last decade, additional verification has not been conducted for scale validation. In particular, the items about nipple problems may not be core items in a tool for assessing breastfeeding adaptation because wounds and pain of the nipple are rarely found at 4 weeks postpartum [8]. The importance of breastfeeding support is also decreasing, as mothers are becoming increasingly able to breastfeed themselves by themselves at 4 weeks postpartum [8]. Therefore, it is necessary to confirm whether the items of the discomfort in breastfeeding sub-dimension and the getting support sub-dimension are in fact necessary to evaluate breastfeeding adaptation. In addition, the reliability of the discomfort in breastfeeding sub-dimension and the getting support sub-dimension of the BFAS scale was low [2]. This study aimed to verify construct validity through confirmatory factor analysis as part of the validation process of the measurement scale, which has not been done previously, and to suggest a shortened scale comprising only core questions.

The original scale is applicable to breastfeeding women at 4 weeks from childbirth, known as the period of adjustment to breastfeeding [2]. Some studies applied this scale to women at less than 4 weeks after childbirth, for whom the validity and reliability had not been evaluated [5,9], and reported that the degree of adaptation to breastfeeding varied according to the postpartum period $(1,4$, and 8 weeks) [5]. The validity of the scale has yet to be confirmed within the first 4 weeks postpartum, before the usual time point for assessing adaptation to breastfeeding.

It takes 2 6 weeks after childbirth for the mother to get acquainted with her baby, learn about her newborn, and physically recover, and 2 weeks to 4 months to move toward a new normal [10]. It takes roughly 10 days for transitional breast milk to mature, and for the established lactation to start to be maintained by the auto-secretion system [11]. It takes approximately 4 weeks to adjust to breastfeeding [8]. Despite individual variance, it generally takes 2 weeks from childbirth to adapt to breastfeeding, and in most cases, adjustment to breastfeeding occurs within approximately 4 weeks from childbirth. Thus, the process of adaptation to breastfeeding is completed in the first 2 weeks postpartum in the physiological, self-con- cept, role function, and interdependence modes, if it is rapid. The process may take more than 4 weeks in case of problems. Therefore, it is important for mothers to assess their level of adaptation to breastfeeding on their own, and to continue to do so after the initial adaptation process. For this reason, it is necessary to evaluate the validity and reliability of the scale used to assess adaptation to breastfeeding to determine its adequacy for use with mothers at 2 weeks from childbirth and to assess whether the longitudinal measurement invariance (MI) of the scale is maintained, making it suitable to compare adaptation to breastfeeding between the first 2 and 4 weeks.

The MI of a scale is essential for comparing the scores of variables across multiple groups defined according to different characteristics (age, gender, time point, etc.). The measurement scores between two groups can be compared more stably if consistency is present in the types of factors of the scale measuring a certain concept and each factor's indicator variables, factor load, intercept, variance and covariance, and error variance [12]. Consistent results of adaptation to breastfeeding according to the age and education of breastfeeding mothers have been reported [3,6,13]. Conversely, inconsistent results of adaptation to breastfeeding or breastfeeding practices according to employment status $[3,4,6,13,14]$, parity $[3,4,6,14]$, and delivery mode $[14,15]$ have been reported. If any multi-group difference is assumed without checking group invariance, errors may occur in interventions, resulting in unnecessary costs. The MI of the scale should first be verified to compare differences across multiple groups in adaptation to breastfeeding, and a latent mean analysis should be performed to compare the mean level of adaptation in order to obtain accurate results. This study reports the MI of the scale and the results of the latent mean analysis at 4 weeks postpartum. The construct validity, reliability, MI of the scale, and results of the latent mean analysis at 2 weeks postpartum will be reported in a subsequent study.

Therefore, this study presents the development of an abbreviated version of the BFAS (yielding the Breastfeeding Adaptation Scale-Short Form, or BFAS-SF), confirmation of its validity and reliability, and suggestions regarding the applicability of the BFAS-SF. Additionally, by measuring the MI of the BFAS-SF at 4 weeks postpartum, this study derived implications regarding future breastfeeding adaptation assessment. Furthermore, the latent variable means of the BFAS-SF were calculated and presented.

\section{Objectives}

This study was conducted to develop the BFAS-SF, to assess its validity and reliability, and to verify the MI of the scale and differences in adaptation to breastfeeding. First, construct 
validity and internal consistency reliability of BFAS-SF at 4 weeks postpartum were verified. Second, the MI of the BFAS-SF was verified depending on the mother's employment status, parity, and delivery mode at 4 weeks postpartum and according to length of postpartum period (2 vs 4 weeks). Third, if any intercept invariance according to employment status, parity, delivery mode, and length of postpartum period was found, between-group differences in the latent variable means of the BFAS-SF were confirmed.

\section{METHODS}

\section{Study Design}

This is a methodological research study conducted to develop a short form of the BFAS (the BFAS-SF) and to test its validity, reliability, and MI.

\section{Participants}

The target group comprised breastfeeding Korean women at 2 weeks postpartum (14 20 days) who voluntarily participated in the survey. These new mothers and babies had not been hospitalized for any disease after birth. The 4-week postpartum group comprised breastfeeding women who participated in the study by responding to the first survey.

For confirmatory factor analysis of the BFAS-SF, the minimum sample size was 109 individuals (Cronbach's $\alpha$ was .05 , degrees of freedom $=296$, power $=.90$, null root mean square error of approximation $[\mathrm{RMSEA}]=.00$, and alternative RMSEA=.05) [16]. Furthermore, 218 individuals were needed to assess the MI between the two groups. Considering possible primary and secondary dropout rates of $30 \%$, respectively, 500 was set as the sample size. Of the 500 questionnaires distributed, 444 completed questionnaires were returned; 431 questionnaires were used for data analysis, excluding incomplete questionnaires; and 272 individuals responded to the second survey.

\section{Instruments}

\section{1) Breastfeeding adaptation scale}

Breastfeeding adaptation was measured using the BFAS [2] after obtaining permission. The BFAS is a 27-item questionnaire assessing eight sub-dimensions of breastfeeding adaptation: emotional exchange with one's baby (4 items), breastfeeding confidence (5 items), sufficient breast milk (3 items), baby's feeding capability and growth (4 items), being familiar with one's baby (4 items), discomfort in breastfeeding (3 items), maintenance of breast milk volume (2 items), and get- ting support ( 2 items). Items are rated on a 5-point Likert scale from 1 (disagree) to 5 points (absolutely agree) (Appendix 1). Items are averaged into eight sub-dimensions of scale scores and a total score; values of the scale scores can range between 1 and 5. A higher score indicates higher breastfeeding adaptation. Cronbach's $\alpha$ of the overall BFAS was .82 and that of its sub-dimensions was .46 .84.

\section{Data Collection}

Data for this study were collected from December 15, 2017 to May 31, 2018. Data for the first survey at 2 weeks postpartum were collected through convenience sampling at 10 postpartum care centers in Seoul, Daegu, Gwangju, Busan, and Gyeongsang Province. As outsiders are not allowed to enter postpartum care centers to keep infants safe from infection, the researcher hired an employee at each postpartum care center as a research assistant. The assistants provided an oral explanation on the study to the subjects at 2 weeks postpartum, and then distributed the questionnaires to those who agreed to take part in the study and collected their responses upon completion. Small gifts (5,000 Korean won) were given to the participants to express gratitude. In the first survey, the questionnaire gathered information on sociodemographic characteristics, obstetric characteristics, and breastfeeding adaptation.

The second survey was distributed online through social networking services or e-mail to those who agreed to data collection at 4 weeks postpartum and provided their phone number or e-mail address directly. The second survey reexamined the current health status of the baby and breastfeeding adaptation in mothers.

\section{Data Analysis}

Values for the frequency and percentage of the subjects' demographic characteristics were calculated, and the mean, standard deviation, skewness, and kurtosis of items and factors were assessed using SPSS version 25.0 (IBM Corp., Armonk, NY, USA). Cronbach's $\alpha$ and 95\% confidence intervals (CIs) were obtained to assess internal consistency reliability.

To verify construct validity, confirmatory factor analysis was performed using AMOS version 25.0 (IBM Corp., Armonk, NY, USA). The following goodness-of-fit indices were used to evaluate the fit of the models: chi-square $\left(x^{2}\right)$, the comparative fit index (CFI; cut-off $>.900$ ), RMSEA (cut-off $<.060$ ), and the standardized root mean residual (SRMR; cut-off $<.0800$ ) $[17,18]$. Items were deleted by based on a review of their standardized regression coefficient (cut-off $<.50$ ), squared multiple correlation (SMC; cut-off $<.30$ ), and modified indices (cut-off 
$\geq 4.0$ ), as well as by theoretically reviewing the content of the items [17]. To confirm the convergent validity of the BFAS-SF, standardized regression coefficients of the observation variables (cut-off $\geq 50$ ), construct reliability (CR; cut-off $\geq 0.70$ ), and average variance extracted (AVE; cut-off $\geq 0.50$ ) were examined. To confirm the discriminant validity of the BFAS-SF, the factor correlation coefficient (cut off $\leq .80$ ) and the AVE of the latent variables and the squared correlation coefficient between latent variables (AVE of latent variable $>$ squared correlation coefficient between latent variables) were examined [17].

Tests of the MI between the two groups according to employment status, parity, delivery mode, and the postpartum period were performed using the BFAS-SF. The test of the MI involved five steps. The first step was configural invariance (factor structure), the second step was metric invariance (factor loading invariance), the third scalar invariance (intercept invariance), the fourth step was factor variance invariance and factor covariance invariance, and the fifth step was error variance invariance. When MI was rejected at each step, partial MI was confirmed. A change in the model fit in MI testing is generally indicated by an increased $x^{2}$ value relative to the increased degrees of freedom, but the $x^{2}$ value was not used here because it is affected by sample size. MI was tested using change in CFI ( $\triangle \mathrm{CFI})$ as the main criterion, and change in RMSEA ( $\triangle$ RMSEA) and change in SRMR $(\triangle S R M R)$ as additional criteria [19]. If the total sample size is smaller than 300 or the sample size between the two groups is not even, as in this study, differences in fit between nested models can be evaluated using cutoffs of $\triangle \mathrm{CFI} \leq .005, \triangle \mathrm{RMSEA} \leq .010, \triangle$ $\mathrm{SRMR} \leq .0250$ (for metric invariance), and $\triangle \mathrm{SRMR} \leq .0050$ (for scalar invariance and error variance invariance) as indicative of a nonsignificant decrease in fit across models [19].

When the scalar invariance was verified, the group mean differences in latent variables were tested.

\section{Ethical Considerations}

All data were collected after Institutional Review Board (IRB) approval (approval number: CUIRB-2017-0079). The purpose of the study, data collection procedure, confidentiality and anonymity, and possibility of withdrawal were explained to the 2-week postpartum participants. An explanation was also given of the data processing procedure, in which data were encrypted, stored separately on a storage device, and completely deleted after the end of the study. The plan to conduct additional data collection at 4 weeks after birth was explained. Participants voluntarily signed an agreement to participate.

\section{RESULTS}

\section{Demographic Characteristics of Participants at 2 and 4 Weeks Postpartum}

The general background characteristics of participants at 2 and 4 weeks postpartum are described in Table 1 . The majority of the participants at 2 and 4 weeks postpartum were employed (51.4\% and 52.2\%, respectively). The proportion of primiparous participants at 2 and 4 weeks postpartum was $73.3 \%$ and $72.1 \%$, respectively. In both groups, the majority of the participants had a vaginal birth $(51.7 \%$ and $55.1 \%$, respectively).

\section{Validation and Reliability of the BFAS-SF at 4 Weeks Postpartum}

Confirmatory factor analysis was conducted on the 27 items and eight factors of the BFAS. The fit of the model was unacceptable: $x^{2}=511.02(p<.001)$, degrees of freedom $=296$, $\mathrm{CFI}=.805, \mathrm{RMSEA}=.086, \mathrm{SRMR}=.0934$. Considering the modified indices and model fit, items with a lower standardized regression coefficient or SMC than the cut-off point were deleted (items no. 6, 9, 15 18, 21 23, 26, 27). With the final six factors and 16 items, the standardized regression coefficients of all items were $\geq .56$, with an $S M C \geq .32$, with both significant factor variance and error variance (Table 2 ). The model fit was also revealed to be acceptable: $\mathrm{CFI}=.96$, $\mathrm{RMSEA}=.06$, and $\mathrm{SRMR}=.04$, except for $x^{2}=168.78(p<.001$, degrees of freedom=89).

Upon verifying the convergent validity of the BFAS-SF, the $\mathrm{CR}$ of each factor was $\geq .73$; each AVE was also $\geq .57$. After examining the discriminative validity of the factors, the correlation coefficient between factors was found to be .25 .68, and the AVE values of all the latent variables were greater than the square of the correlation coefficient between the latent variables.

The names of the sub-dimensions of the BFAS-SF are as follows: factor 1, emotional exchange with one's baby; factor 2, breastfeeding confidence; factor 3, sufficient breast milk; factor 4 , baby's feeding capability; factor 5 , baby's satisfaction with breastfeeding; factor 6, maintenance of breast milk volume.

The $M \pm S D$, skewness, and kurtosis of the items and $M \pm S D$ of factors of the BFAS-SF are shown in Table 3.

Cronbach's $\alpha(95 \% \mathrm{CI})$ for the overall scale was $.88(.85 \sim$ .90). The Cronbach's $\alpha$ values were as follows for the sub-dimensions: factor $1, .84$ (.80 .87); factor 2, .67 (.59 .73); factor 3 , .78 (.73 .82); factor $4, .75$ (.69 .81); factor $5, .79$ (.74 .84); factor $6, .75$ (.68 .80) (Table 3). 
Table 1. Demographic Characteristics of Participants at Two and Four Weeks Postpartum

\begin{tabular}{|c|c|c|c|}
\hline \multirow{2}{*}{ Variables } & \multirow{2}{*}{ Categories } & Two weeks postpartum $(n=431)$ & Four weeks postpartum $(n=272)$ \\
\hline & & $\mathrm{n}(\%)$ & $\mathrm{n}(\%)$ \\
\hline \multirow[t]{3}{*}{ Age $(\text { year })^{*}$} & $20 \mathrm{~s}$ & $89(20.7)$ & $63(23.2)$ \\
\hline & $30 \mathrm{~s}$ & $323(75.3)$ & $199(73.5)$ \\
\hline & $40 \mathrm{~s}$ & $17(4.0)$ & $9(3.3)$ \\
\hline \multirow[t]{4}{*}{ Education } & High school or below & $37(8.6)$ & $20(7.4)$ \\
\hline & Associate's degree & $100(23.2)$ & $65(23.9)$ \\
\hline & Bachelor's degree & $255(59.2)$ & $159(58.4)$ \\
\hline & Master's degree or higher & $39(9.0)$ & $28(10.3)$ \\
\hline \multirow[t]{2}{*}{ Employment status* } & Yes & $221(51.4)$ & $142(52.2)$ \\
\hline & No & $209(48.6)$ & $130(47.8)$ \\
\hline \multirow[t]{3}{*}{ Family income } & Low & 73 (16.9) & $45(16.5)$ \\
\hline & Middle & $255(59.2)$ & $165(60.7)$ \\
\hline & High & $103(23.9)$ & $62(22.8)$ \\
\hline \multirow{2}{*}{$\begin{array}{l}\text { Current health status of } \\
\text { the baby }\end{array}$} & Healthy & $431(100.0)$ & $272(100.0)$ \\
\hline & Not healthy & $0(0.0)$ & $0(0.0)$ \\
\hline \multirow[t]{4}{*}{ Gestation period* } & 35 weeks or below & $2(0.5)$ & $1(0.4)$ \\
\hline & 35 weeks 1 day to 37 weeks & $19(4.4)$ & $10(3.7)$ \\
\hline & 37 weeks 1 day to 42 weeks & 407 (94.6) & $258(95.2)$ \\
\hline & 42 weeks 1 day or over & $2(0.5)$ & $2(0.7)$ \\
\hline \multirow[t]{2}{*}{ Parity } & Primipara & $316(73.3)$ & $196(72.1)$ \\
\hline & Multipara & $115(26.7)$ & $76(27.9)$ \\
\hline \multirow[t]{3}{*}{ Number of children } & 1 & $316(73.3)$ & $196(72.1)$ \\
\hline & 2 & $92(21.4)$ & $61(22.4)$ \\
\hline & 3 or more & $23(5.3)$ & $15(5.5)$ \\
\hline \multirow[t]{2}{*}{ Delivery mode } & Vaginal delivery & $223(51.7)$ & $150(55.1)$ \\
\hline & Caesarean section & $208(48.3)$ & $122(44.9)$ \\
\hline \multirow{2}{*}{$\begin{array}{l}\text { Current breast feeding } \\
\text { experience }\end{array}$} & First & $324(75.2)$ & $197(72.4)$ \\
\hline & Second or more & $107(24.8)$ & 75 (27.6) \\
\hline
\end{tabular}

*Missing data were excluded.

\section{Measurement Invariance Test of the BFAS-SF}

In MI testing of the BFAS-SF according to mother's employment status (being employed or not), the fit indexes were acceptable for configural (factor structure) invariance. Although metric invariance was not supported (with a $\triangle \mathrm{CFI}>.005$ ), partial metric invariance, partial scalar invariance, partial factor variance (covariance), and partial error variance invariance were achieved (with a $\triangle \mathrm{CFI} \leq .005$ and a $\triangle$ RMSEA $\leq$ .0100 ), with 15 indicators (except for item no. 25, 'trying to eat enough food and water for breastfeeding') having equal factor loadings, item intercepts, factor variance (covariance), and error variance across groups (Table 4).

In MI testing of the BFAS-SF across parity (primipara or multipara), configural and metric invariance were achieved (with a $\triangle \mathrm{CFI} \leq .005$, a $\triangle \mathrm{RMSEA} \leq .010$, and a $\triangle \mathrm{SRMR} \leq .0250$ ), with all indicators having equal factor structure and factor loadings (Table 4).

In MI testing of the BFAS-SF across delivery mode (vaginal or cesarean delivery), configural, metric, and scalar invariance were achieved (with a $\triangle \mathrm{CFI} \leq .005$, a $\triangle \mathrm{RMSEA} \leq .010$, a $\triangle S R M R \leq .0050$ ), with all indicators having equal factor structure, factor loadings, and item intercepts across groups (Table 4 ).

The longitudinal MI of the BFAS-SF at 2 and 4 weeks postpartum was examined. The fit indexes were acceptable for configural (factor structure) invariance. Although metric invariance was not supported (with a $\triangle \mathrm{CFI}>$.005), partial metric invariance was achieved (with a $\triangle \mathrm{CFI} \leq .005$, a $\triangle$ RMSEA $\leq .010$, a $\triangle$ SRMR $\leq .0250$ ), with 14 indicators (except for item no. 1 , 'my baby looks so lovely when he or she is drinking breast milk,' and item no. 12, 'my breasts feel full when it is time to feed my baby') having equal factor loadings and item intercepts across groups (Table 4). 
Table 2. Factor Loading and Squared Multiple Correlations of Observational Variables of the Breastfeeding Adaptation Scale-Short Form

$(N=272)$

\begin{tabular}{|c|c|c|c|c|c|c|}
\hline Factors & Observational variables & B & $\beta$ & $\mathrm{CR}$ & $p$ & SMC \\
\hline \multirow[t]{4}{*}{$\mathrm{F} 1$} & Item 1 & 1.00 & .73 & & .032 & $.53^{*}$ \\
\hline & Item 2 & 1.38 & .82 & 13.00 & .030 & $.68^{*}$ \\
\hline & Item 3 & 1.67 & .88 & 12.81 & .012 & $.78^{*}$ \\
\hline & Item 4 & 1.34 & .64 & 9.63 & .020 & $.41^{*}$ \\
\hline \multirow[t]{3}{*}{ F2 } & Item 5 & 1.00 & .66 & & .012 & $.44^{*}$ \\
\hline & Item 7 & 0.80 & .81 & 9.59 & .023 & $.65^{*}$ \\
\hline & Item 8 & 0.53 & .56 & 7.36 & .007 & $.32^{* *}$ \\
\hline \multirow[t]{3}{*}{ F3 } & Item 10 & 1.00 & .90 & & .023 & $.82^{*}$ \\
\hline & Item 11 & 0.71 & .75 & 12.46 & .005 & $.56^{* *}$ \\
\hline & Item 12 & 0.47 & .58 & 9.78 & .009 & $.34^{* *}$ \\
\hline \multirow[t]{2}{*}{ F4 } & Item 13 & 1.00 & .84 & & .018 & $.71^{*}$ \\
\hline & Item 14 & 0.71 & .73 & 9.87 & .013 & $.53^{*}$ \\
\hline \multirow[t]{2}{*}{ F5 } & Item 19 & 1.00 & .88 & & .025 & $.78^{*}$ \\
\hline & Item 20 & 0.85 & .75 & 12.24 & .006 & $.56^{* *}$ \\
\hline \multirow[t]{2}{*}{ F6 } & Item 24 & 1.00 & .75 & & .005 & $.57^{* *}$ \\
\hline & Item 25 & 0.94 & .79 & 6.35 & .019 & $.63^{*}$ \\
\hline
\end{tabular}

${ }^{*} p<.050 ;{ }^{* *} p<.010 ; \beta=$ standardized regression coefficient; $\mathrm{CR}=$ Critical ratio; SMC=Squared multiple correlation; F1=Emotional exchange with one's baby; F2=Breastfeeding confidence; F3=Sufficient breast milk; F4=Baby's feeding capability; F5=Baby's satisfaction with breastfeeding; F6=Maintenance of breast milk volume.

Table 3. Descriptive Statistics of the Breastfeeding Adaptation Scale-Short Form

$(N=272)$

\begin{tabular}{|c|c|c|c|c|c|c|c|c|c|}
\hline \multirow{2}{*}{ Factors } & \multirow{2}{*}{ No of items } & \multicolumn{3}{|c|}{ Items } & \multicolumn{3}{|c|}{ Factors } & \multirow{2}{*}{ Cronbach's $\alpha$} & \multirow{2}{*}{$95 \% \mathrm{CI}$} \\
\hline & & $\mathrm{M} \pm \mathrm{SD}$ & Skewness & Kurtosis & $\mathrm{M} \pm \mathrm{SD}$ & Skewness & Kurtosis & & \\
\hline \multirow[t]{4}{*}{$\mathrm{F} 1$} & Item 1 & $4.85 \pm 0.36$ & -1.96 & 1.88 & \multirow[t]{4}{*}{$4.21 \pm 0.64$} & \multirow[t]{4}{*}{-0.67} & \multirow[t]{4}{*}{0.31} & \multirow[t]{4}{*}{.84} & \multirow[t]{4}{*}{$.80 \sim .87$} \\
\hline & Item 2 & $4.50 \pm 0.68$ & -1.23 & 1.12 & & & & & \\
\hline & Item 3 & $4.37 \pm 0.72$ & -0.81 & -0.19 & & & & & \\
\hline & Item 4 & $4.16 \pm 0.90$ & -0.72 & -0.35 & & & & & \\
\hline \multirow[t]{3}{*}{ F2 } & Item 5 & $3.94 \pm 1.10$ & -0.74 & -0.47 & \multirow[t]{3}{*}{$3.51 \pm 0.75$} & \multirow[t]{3}{*}{-0.06} & \multirow[t]{3}{*}{-0.42} & \multirow[t]{3}{*}{.67} & \multirow[t]{3}{*}{$.59 \sim .73$} \\
\hline & Item 7 & $3.86 \pm 0.74$ & -0.26 & -0.17 & & & & & \\
\hline & Item 8 & $3.40 \pm 0.78$ & 0.06 & 0.10 & & & & & \\
\hline \multirow[t]{3}{*}{ F3 } & Item 10 & $3.46 \pm 1.07$ & -0.12 & -0.71 & \multirow[t]{3}{*}{$3.53 \pm 0.84$} & \multirow[t]{3}{*}{0.05} & \multirow[t]{3}{*}{-0.67} & \multirow[t]{3}{*}{.78} & \multirow[t]{3}{*}{$.73 \sim .82$} \\
\hline & Item 11 & $3.79 \pm 0.85$ & -0.38 & -0.06 & & & & & \\
\hline & Item 12 & $4.09 \pm 0.92$ & -1.10 & 1.25 & & & & & \\
\hline \multirow[t]{2}{*}{$\mathrm{F} 4$} & Item 13 & $3.69 \pm 1.06$ & -0.54 & -0.34 & \multirow[t]{2}{*}{$3.70 \pm 0.91$} & \multirow[t]{2}{*}{-0.58} & \multirow[t]{2}{*}{0.03} & \multirow[t]{2}{*}{.75} & \multirow[t]{2}{*}{$.69 \sim .81$} \\
\hline & Item 14 & $3.66 \pm 0.92$ & -0.34 & -0.14 & & & & & \\
\hline \multirow[t]{2}{*}{ F5 } & Item 19 & $3.47 \pm 0.95$ & -0.25 & -0.41 & \multirow[t]{2}{*}{$3.37 \pm 0.87$} & \multirow[t]{2}{*}{-0.29} & \multirow[t]{2}{*}{-0.18} & \multirow[t]{2}{*}{.79} & $.74 \sim .84$ \\
\hline & Item 20 & $3.43 \pm 0.97$ & -0.24 & -0.54 & & & & & \\
\hline F6 & Item 24 & $3.85 \pm 0.80$ & -0.56 & 0.57 & $3.63 \pm 0.73$ & -0.09 & -0.38 & .75 & $.68 \sim .80$ \\
\hline & Item 25 & $4.20 \pm 0.65$ & -0.39 & 0.03 & & & & & \\
\hline Total & & & & & $3.71 \pm 0.54$ & -0.01 & -0.17 & .88 & $.85 \sim .90$ \\
\hline
\end{tabular}

CI=Confidence interval; F1=Emotional exchange with one's baby; F2=Breastfeeding confidence; F3=Sufficient breast milk; F4=Baby's feeding capability; F5=Baby's satisfaction with breastfeeding; F6=Maintenance of breast milk volume.

\section{Group Mean Differences in Latent Variables}

At 4 weeks postpartum, mothers who were unemployed had a 0.28-point higher $(p=.018)$ average score for latent variable 2, a 0.38-point higher $(p=.007)$ average score for latent var- iable 3, and a 0.32-point higher $(p=.004)$ average score for latent variable 5 than those who were employed (Table 5).

Mothers who gave birth vaginally had a 0.24-point higher $(p=.028)$ average score for latent variable 2 , a 0.43 -point higher $(p=.002)$ average score for latent variable 3 , and a 0.23-point 
higher $(p=.043)$ average score for latent variable 5 than those who had a cesarean section (Table 5).

\section{DISCUSSION}

This study presented a shortened version of the BFAS that was derived by reexamining the key items and factors on adaptation to breastfeeding and verified its construct validity by conducting confirmatory factor analysis. The results showed acceptable convergent validity and discriminative validity for each factor. The internal consistency reliability of all items of the shortened scale was good $(\geq .80)$. The internal consistency reliability of the sub-dimensions was acceptable $(\geq .70)$, except for confidence in breastfeeding. The BFAS-SF may be valid and reliable for measuring mothers' adaptation to breastfeeding at 4 weeks postpartum. Cronbach's $\alpha$ of the overall scale of BFAS-SF and of its sub-dimensions showed improvement relative to the BFAS. Additionally, the BFAS-SF could be used to assess mothers' breastfeeding adaptation using a subset of core items from the BFAS. Unlike a breastfeeding effectiveness scale recently developed in Korea, the BFAS-SF regards breastfeeding in postpartum care as an adaptation process and measures the adaptation that develops over time [2]. A breastfeeding effectiveness scale, in contrast, is an assessment of the effects of the transfer of breast milk and fulfillment of the needs of the mother on breastfeeding behavior at a sin-

Table 4. Analysis of Measurement Invariance of the Breastfeeding Adaptation Scale-Short Form

$(N=272)$

\begin{tabular}{|c|c|c|c|c|c|c|c|c|c|c|}
\hline \multirow{2}{*}{ Variables } & \multirow{2}{*}{ Invariance model } & \multicolumn{6}{|c|}{ Model fit indices } & \multicolumn{3}{|c|}{ Model comparison } \\
\hline & & $x^{2}$ & $\mathrm{df}$ & $\mathrm{NC}$ & CFI & RMSEA & SRMR & $\triangle \mathrm{CFI}$ & $\triangle$ RMSEA & $\triangle \mathrm{SRMR}$ \\
\hline \multirow{6}{*}{$\begin{array}{l}\text { Employment } \\
\text { status }\end{array}$} & Configural & $280.22^{*}$ & 178 & 1.57 & .944 & .046 & .0640 & & & \\
\hline & Metric & $302.12^{*}$ & 188 & 1.61 & .938 & .047 & .0642 & -.006 & .001 & .0002 \\
\hline & Partial metric $^{\dagger}$ & $299.42^{*}$ & 187 & 1.60 & .939 & .047 & .0642 & -.005 & .001 & .0002 \\
\hline & Partial scalar $^{\dagger}$ & $317.14^{*}$ & 203 & 1.56 & .938 & .046 & .0648 & -.001 & -.001 & .0006 \\
\hline & $\begin{array}{l}\text { Partial factor } \\
\text { variance/covariance }^{\dagger}\end{array}$ & $346.66^{*}$ & 224 & 1.55 & .933 & .045 & .0701 & -.005 & -.001 & .0053 \\
\hline & Partial residual $^{\dagger}$ & $367.53^{*}$ & 240 & 1.53 & .930 & .044 & .0701 & -.003 & -.001 & .0000 \\
\hline \multirow[t]{2}{*}{ Parity } & Configural & $309.74^{*}$ & 178 & 1.74 & .928 & .052 & .0458 & & & \\
\hline & Metric & $325.30^{*}$ & 188 & 1.73 & .925 & .052 & .0454 & -.003 & .000 & -.0030 \\
\hline \multirow{3}{*}{$\begin{array}{l}\text { Delivery } \\
\text { mode }\end{array}$} & Configural & $260.36^{*}$ & 178 & 1.46 & .955 & .041 & .0484 & & & \\
\hline & Metric & $268.28^{*}$ & 188 & 1.43 & .956 & .040 & .0486 & .001 & -.001 & .0000 \\
\hline & Scalar & $291.39 *$ & 204 & 1.43 & .952 & .040 & .0484 & -.004 & .000 & .0000 \\
\hline \multirow{3}{*}{$\begin{array}{l}\text { Postpartum } \\
\text { period }\end{array}$} & Configural & $334.46^{*}$ & 178 & 1.88 & .952 & .040 & .0550 & & & \\
\hline & Metric & $371.82^{*}$ & 188 & 1.98 & .944 & .042 & .0610 & -.008 & .002 & .0060 \\
\hline & Partial metric ${ }^{\dagger}$ & $340.92^{*}$ & 186 & 1.83 & .953 & .039 & .0574 & .001 & -.001 & .0024 \\
\hline
\end{tabular}

${ }^{*} p<.001 ;{ }^{\dagger}$ All items except item no. $25 ;{ }^{\dagger}$ All items except item no. 1 and $12 ; \mathrm{df}=$ Degree of freedom; NC=Normed Chi-square; CFI=Comparative fit index; RMSEA=Root mean square error of approximation; SRMR=Standardized root mean residual; $\triangle \mathrm{CFI}=\mathrm{Comparative} \mathrm{fit} \mathrm{index} \mathrm{difference;}$ $\triangle$ RMSEA=Root mean square error of approximation difference; $\triangle \mathrm{SRMR}=$ Standardized root mean residual difference.

Table 5. Group Mean Differences in Latent Variables at Four Weeks Postpartum

$(N=272)$

\begin{tabular}{|c|c|c|c|c|c|}
\hline Variables & Factors & Mean & SE & CR & $p$ \\
\hline $\begin{array}{l}\text { Employment status } \\
\text { (unemployment)* }\end{array}$ & $\begin{array}{l}\text { F1 } \\
\text { F2 } \\
\text { F3 } \\
\text { F4 } \\
\text { F5 } \\
\text { F6 }\end{array}$ & $\begin{array}{l}0.04 \\
0.28 \\
0.38 \\
0.24 \\
0.32 \\
0.03\end{array}$ & $\begin{array}{l}.06 \\
.12 \\
.14 \\
.13 \\
.11 \\
.10\end{array}$ & $\begin{array}{l}0.69 \\
2.36 \\
2.70 \\
1.91 \\
2.92 \\
0.34\end{array}$ & $\begin{array}{l}.493 \\
.018 \\
.007 \\
.057 \\
.004 \\
.738\end{array}$ \\
\hline $\begin{array}{l}\text { Delivery mode } \\
\text { (vaginal delivery) }^{\dagger}\end{array}$ & $\begin{array}{l}\text { F1 } \\
\text { F2 } \\
\text { F3 } \\
\text { F4 } \\
\text { F5 } \\
\text { F6 }\end{array}$ & $\begin{array}{l}0.02 \\
0.24 \\
0.43 \\
0.16 \\
0.23 \\
0.09\end{array}$ & $\begin{array}{l}.06 \\
.11 \\
.14 \\
.13 \\
.11 \\
.09\end{array}$ & $\begin{array}{l}0.29 \\
2.20 \\
3.16 \\
1.24 \\
2.02 \\
1.04\end{array}$ & $\begin{array}{l}.771 \\
.028 \\
.002 \\
.216 \\
.043 \\
.299\end{array}$ \\
\hline
\end{tabular}

*Reference variable is employment; ${ }^{\dagger}$ Reference variable is cesarean section; $\mathrm{SE}=\mathrm{Standard}$ error; $\mathrm{CR}=\mathrm{Critical}$ ratio; F1=Emotional exchange with one's baby; F2=Breastfeeding confidence; F3=Sufficient breast milk; F4=Baby's feeding capability; F5=Baby's satisfaction with breastfeeding; F6=Maintenance of breast milk volume. 
gle point in time [20]. Thus, the BFAS-SF can be used to assess the adaptive state of breastfeeding, not breastfeeding behavior at a moment in time.

Regarding the items of the BFAS-SF, two items about the baby's growth (baby's health skin condition and weight gain) were deleted from the fourth factor of the original scale dealing with "the baby's feeding capability and growth", leaving the items about baby's feeding capability (latching, rhythmic sucking/swallowing patterns) because new mothers generally cannot identify or interpret slight differences in the baby's skin condition and weight gain at 2 and 4 weeks postpartum, whereas it is easier for them to recognize the feeding capability of their babies. Numerous scales exist for measuring babies' feeding capability [20-22], but fewer measure babies' growth [23], suggesting that the baby's feeding capability is a core factor for assessing adaptation to breastfeeding.

All three items about wounds and pain of the nipple and fatigue in the original factor "discomfort in breastfeeding" were deleted in the BFAS-SF. The scales currently used to measure discomfort in breastfeeding women in postpartum hospitals within the admission period [21,22]. The H\&H lactation scale [24] and the breastfeeding self-efficacy scale [25] have no items about discomfort while breastfeeding, even though they are available at 4 weeks postpartum. Wounds and pain of nipples and fatigue should be assessed within the first week after childbirth, but these symptoms are rarely observed at 4 weeks postpartum. They are considered to be less critical during this time.

The eighth factor, "getting support", was deleted from the BFAS-SF. If a mother has successfully adapted to breastfeeding, she should be capable of breastfeeding without support. This factor had the lowest explained variance and internal consistency reliability during development [2]. A scale [25] on breastfeeding at 4 weeks postpartum included only one item on this factor. Thus, items associated with this factor are considered to be less critical regarding adaptation to breastfeeding.

MI (cross validity) was confirmed as part of verifying the validity of BFAS-SF. Strict MI of the BFAS-SF was achieved, except for item no. 25 (trying to eat enough food and water for breastfeeding) between the groups divided by employment status. The reason why the MI of item no. 25 was not established may be interpreted in terms of the influence of returning to work. In other words, because of the clear correlation between proper food intake and breast milk production [11], employed mothers were likely to reduce their food intake to stop breastfeeding and return to work.

This study verified the configural and metric invariance of the BFAS-SF between primiparous and multiparous groups. It was also found that equivalence could not be ensured due to the large difference in the intercepts for many items on adaptation to breastfeeding between the groups. The difference in the intercepts between primiparous and multiparous mothers may be explained by differences in readiness due to breastfeeding experience. That is, maternal stress is negatively correlated with breast milk production and ejection reflex [26], and multiparous mothers are more likely to have previous breastfeeding experience and more knowledge, leading to fewer problems with breastfeeding than experienced by primiparous mothers. Multiparous mothers produce more breast milk and have a larger milk storage capacity, as parity affects both the rate and pattern of mammary gland alveolar development [27]. Thus, it may be possible to compare the score of items of BFAS-SF between primiparous and multiparous groups, but not to compare the mean scores of the sub-dimensions.

Strict measurement equivalence between vaginal and cesarean delivery groups at 4 weeks postpartum was achieved. The effects of the delivery mode on breastfeeding adaptation are estimated to be insignificant at 4 weeks after delivery. Therefore, in future studies, it may be possible to compare the mean scores of the sub-dimensions of the BFAS-SF between mothers who underwent vaginal and cesarean delivery.

Metric invariance in the longitudinal MI of the BFAS-SF between 2 and 4 weeks postpartum was established for all items except item no. 1 (my baby looks so lovely when he or she is drinking breast milk) and no.12 (my breasts feel full when it is time to feed my baby). This indicates a difference in the factor loading between the two groups for these two items, with the mothers at 4 weeks postpartum being more likely to be attached to their baby than the mothers at 2 weeks because the former group has interacted with their baby for longer. Breast milk matures in roughly 10 days postpartum, after which the preset milk production is maintained at a steady rate and adjusted through an autocrine mechanism in which the law of milk supply responds to demand [11]. At 4 weeks postpartum, mothers have likely attained a stable pattern of breast milk production and ejection reflex, allowing them to better recognize the feeling of fullness in their breasts when it is time to feed their babies than those at 2 weeks postpartum. In future studies, it may be possible to compare the scores of items of the BFAS-SF between mothers at 2 and 4 weeks postpartum, but not to compare the mean scores of the sub-dimensions.

In this study, unemployed mothers had higher latent mean values of confidence in breastfeeding, sufficient breast milk, and baby's satisfaction with breastfeeding than those who were employed. Women who were unemployed engaged in breastfeeding more often than women who were employed, and women who engaged in exclusive breastfeeding had higher self-confidence [28]. When mothers who were employed 
face breastfeeding problems, they may decide to stop breastfeeding to return to work. Their breast milk production may then gradually decrease, along with decreases in the frequency of breastfeeding, confidence in breastfeeding, and the baby's satisfaction with breastfeeding. As mothers' employment status was examined in this study, further studies should longitudinally examine interactions among the time to return to work, current work status, and adaptation to breastfeeding.

Mothers who gave birth vaginally had higher latent means for confidence in breastfeeding, sufficient breast milk, and their baby's satisfaction with breastfeeding than those who had a cesarean section. Mothers who give birth vaginally have a more advantageous start in breastfeeding than those who have a cesarean delivery. At 24 hours postpartum, levels of prolactin and oxytocin in sera of mothers who underwent a cesarean section under general anesthesia were lower than those who had a vaginal birth [29]. Those who had a cesarean delivery had fewer instances of first breastfeeding within an hour after delivery and less frequent breastfeeding than those who had a vaginal birth [30]. Due to these advantages, mothers who had a vaginal delivery reached a more mature stage at 4 weeks postpartum, resulting in higher confidence in breastfeeding, breast milk volume, and their baby's satisfaction with breastfeeding than mothers who had a cesarean delivery. For mothers struggling to adapt to breastfeeding after cesarean section, further measures are needed to improve their confidence in breastfeeding, breast milk, and baby's satisfaction with breastfeeding.

Adaptation to breastfeeding is crucial for the health of both the mother and baby. Individualized nursing interventions can improve the long-term breastfeeding rate of mothers after assessing their adaptation to breastfeeding at 2 and 4 weeks postpartum. Nurses at hospitals and community health centers can develop programs to improve mothers' adaptation to breastfeeding and assess the effects of such programs using the BFAS-SF.

Despite the difficulty in collecting data from new mothers due to the ultra-low birth rate in Korea, an attempt was made to gather data from new mothers at multiple institutions in various regions of the country to ensure the representativeness of the data. Nonetheless, the data were collected through convenience sampling from four cities and one province, and only mothers using postpartum care centers were investigated. The results of this study therefore may not represent the entire population of mothers who have recently given birth in Korea, and cannot be generalized because this study did not include data from new mothers who did not stay at a postpartum care center. Moreover, this study assessed the construct validity, reliability, and MI of the BFAS-SF among mothers at 4 weeks postpartum, but not the criterion-related val- idity, which should be assessed in further studies. The findings on the psychometric properties of the BFAS-SF at 2 weeks postpartum that were not reported in this article will be presented in subsequent paper.

\section{CONCLUSION}

This study presented the BFAS-SF, a shortened version of the BFAS that reduced the original 27 questions to 16 questions, and verified the construct validity, MI, and reliability at 4 weeks postpartum. The six sub-dimensions of the BFAS-SF consisted of emotional exchange with one's baby, breastfeeding confidence, sufficient breast milk, baby's feeding capability, baby's satisfaction with breastfeeding, and maintenance of breast milk volume. The BFAS-SF was found to be a valid and reliable tool applicable to new mothers. The MI among multiple was examined according to employment status, parity, delivery mode, and postpartum period, and suggestions were made regarding comparison and analysis of adaptation to breastfeeding. In future studies, careful interpretation of differences in item scores according to employment status and mean comparisons of the sub-dimensions is required. It is possible to compare differences in item scores both between parity groups and between postpartum period groups, but the degree to which mean values of the sub-dimensions of the BFAS-SF can be compared is limited. It is also possible to compare mean values of the sub-dimensions of the BFAS-SF among delivery modes. This scale will hopefully be used to assess adaptation to breastfeeding and the effects of related programs.

\section{Conflict of interest}

No existing or potential conflict of interest relevant to this article was reported.

\section{REFERENCES}

1. Lee SY. Results of the 2018 postpartum care survey [Internet]. Sejong, Korea: Ministry of Health and Welfare; 2019 [cited 2019 February 20]. Available from: http://www.mohw.go.kr/react/jb/sjb030301vw.jsp?PAR_MEN U_ID=03\&MENU_ID=032901\&CONT_SEQ=347424\&page=1.

2. Kim SH. Development of a breast feeding adaptation scale (BFAS). Journal of Korean Academy of Nursing. 2009;39(2):259-269. https://doi.org/10.4040/jkan.2009.39.2.259

3. Kim SH. Factors affecting mother's adaptation to breastfeeding. Journal of Korean Academy of Nursing. 2010;40(2):225-235. https://doi.org/10.4040/jkan.2010.40.2.225

4. Kim YK. Adaptation of breastfeeding and maternal self-efficacy of 
mothers with infants [master's thesis]. Seoul: Ewha Womans University; 2010. p. 1-62.

5. Song SM, Park MK. Effects of breastfeeding empowerment program on breastfeeding self-efficacy, adaptation and continuation in primiparous women. Journal of Korean Academy of Nursing. 2016;46(3):409-419. https://doi.org/10.4040/jkan.2016.46.3.409

6. Ahn S, Kim Y. Association of parenting stresses, maternal role adjustment, and types of feeding during hospital stays at birth to breastfeeding adaptation. Korean Journal of Women Health Nursing. 2015;21(4):262-271.

https://doi.org/10.4069/kjwhn.2015.21.4.262

7. Yun MH, Shin HS. Comparison of lactation problems, knowledge, and adaptation on breastfeeding between users and non-users of lactation clinic. Journal of East-West Nursing Reseach. 2014;20(2): 112-120. https://doi.org/10.14370/jewnr.2014.20.2.112

8. Huggins $\mathrm{K}$, Ziedrich L. The nursing mother's guide to weaning. 2nd ed. Boston, MA: The Harvard Common Press; 2007. p. 26-29.

9. Yun SE, Lee HK. Effects of breast-feeding adaptation, attitude and practice of primipara depending on method of postpartum breastfeeding education. Korean Journal of Women Health Nursing. 2012;18(2):75-84. https://doi.org/10.4069/kjwhn.2012.18.2.75

10. Mercer RT. Becoming a mother versus maternal role attainment. Journal of Nursing Scholarship. 2004;36(3):226-232. https://doi.org/10.1111/j.1547-5069.2004.04042.x

11. Lawrence RA, Lawrence RM. Breastfeeding: A guide for the medical profession. 8th ed. Philadelphia, PA: Elsevier; 2015. p. 102-108, 284.

12. Van De Schoot R, Schmidt P, De Beuckelaer A, Lek K, Zondervan-Zwijnenburg M. Editorial: Measurement invariance. Frontiers in Psychology. 2015:6;1064.

https://doi.org/10.3389/fpsyg.2015.01064

13. Heo SH, Noh YG. Impact of parenting stress and husband's support on breastfeeding adaptation among breastfeeding mothers. Korean Journal of Women Health Nursing. 2017;23(4):233-242. https://doi.org/10.4069/kjwhn.2017.23.4.233

14. Al Juaid DA, Binns CW, Giglia RC. Breastfeeding in Saudi Arabia: A review. International Breastfeeding Journal. 2014;9:1. https://doi.org/10.1186/1746-4358-9-1

15. Prior E, Santhakumaran S, Gale C, Philipps LH, Modi N, Hyde MJ. Breastfeeding after cesarean delivery: A systematic review and meta-analysis of world literature. The American Journal of Clinical Nutrition. 2012;95(5):1113-1135.

https://doi.org/10.3945/ajcn.111.030254

16. Preacher KJ, Coffman DL. Computing power and minimum sample size for RMSEA (softwear) [Internet]. Nashville: Kristopher J. Preacher; 2006 [cited 2018 September 20]. Available from: http://www.quantpsy.org/rmsea/rmsea.htm.

17. Brown TA. Confirmatory factor analysis for applied research. 2nd ed. United States of America: The Guilford Press; 2015. p. 46-76.

18. Marsh HW, Hau KT, Wen Z. In search of golden rules: Comment on hypothesis-testing approaches to setting cutoff values for fit indexes and dangers in overgeneralizing $\mathrm{Hu}$ and Bentler's (1999) findings. Structural Equation Modeling: A Multidisciplinary Journal. 2004;11(3):320-341.

https://doi.org/10.1207/s15328007sem1103_2

19. Chen FF. Sensitivity of goodness of fit indexes to lack of measurement invariance. Structural Equation Modeling: A Multidisciplinary Journal. 2007;14(3):464-504.

https://doi.org/10.1080/10705510701301834

20. Yang HJ, Seo JM. Concept analysis of effective breastfeeding. Korean Journal of Women Health Nursing. 2011;17(4):317-427. https://doi.org/10.4069/kjwhn.2011.17.4.317

21. Johnson TS, Mulder PJ, Strube K. Mother-infant breastfeeding progress tool: A guide for education and support of the breastfeeding dyad. Journal of Obstetric, Gynecologic, and Neonatal Nursing. 2007;36(4):319-327.

22. Mulford C. The mother-baby assessment (MBA): An "apgar score" for breastfeeding. Journal of Human Lactation. 1992;8(2):79-82. https://doi.org/10.1177/089033449200800216

23. Leff EW, Jefferis SC, Gagne MP. The development of the maternal breastfeeding evaluation scale. Journal of Human Lactation. 1994; 10(2):105-111. https://doi.org/10.1177/089033449401000217

24. Hill PD, Humenick SS. Development of the H \& H lactation scale. Nursing Research. 1996;45(3):136-140.

25. Dennis CL, Faux S. Development and psychometric testing of the breastfeeding self-efficacy scale. Research in Nursing \& Health. 1999;22(5):399-409.

https://doi.org/10.1002/(SICI)1098-240X(199910)22:5<399::AIDNUR6>3.0.CO;2-4

26. Dewey KG. Maternal and fetal stress are associated with impaired lactogenesis in humans. The Journal of Nutrition. 2001;131(11): 3012S-3015S. https://doi.org/10.1093/jn/131.11.3012S

27. Lang SLC, Iverson SJ, Bowen WD. Primiparous and multiparous females differ in mammary gland alveolar development: Implications for milk production. Journal of Experimental Biology. 2012;215(16): 2904-2911. https://doi.org/10.1242/jeb.067058

28. Wahyuni AT, Handayani L, Rahmadani A. Correlation between education, occupation, family income, and self confidence with exclusive breastfeeding. Jurnal Kedokteran dan Kesehatan Indonesia. 2016;7(3):115-122. https://doi.org/10.20885/JKKI.Vol7.Iss3.art7

29. Kutlucan L, Seker IS, Demiraran Y, Ersoy Ö, Karag öz I, Sezen G, et al. Effects of different anesthesia protocols on lactation in the postpartum period. Journal of the Turkish German Gynecological Association. 2014;15(4):233-238.

https://doi.org/10.5152/jtgga.2014.14111

30. Prado DS, Mendes RB, Gurgel RQ, Barreto IDC, Cipolotti R, Gurgel RQ. The influence of mode of delivery on neonatal and maternal short and long-term outcomes. Revista de Saúde Pública. 2018;52:95. https://doi.org/10.11606/s1518-8787.2018052000742 


\section{Appendix 1. Sub-dimensions and Items of the Breastfeeding Adaptation Scale}

\begin{tabular}{|c|c|}
\hline Sub-dimensions & Items \\
\hline Emotional exchange with one's baby & $\begin{array}{l}\text { 1. My baby looks so lovely when he or she is drinking breast milk. } \\
\text { 2. I feel the exchange of good emotions while breastfeeding my children. } \\
\text { 3. I am happy during breastfeeding. } \\
\text { 4. I seem to have become a true mother when breastfeeding. }\end{array}$ \\
\hline Breastfeeding confidence & $\begin{array}{l}\text { 5. I am going to breast feed for over six months. } \\
\text { 6. I can make my baby latch on my breasts again when my baby does not latch on well. } \\
\text { 7. I can endure breastfeeding even with difficulties. } \\
\text { 8. I know well about how to feed breast milk. } \\
\text { 9. I can get reliable information about breastfeeding. }\end{array}$ \\
\hline Sufficient breast milk & $\begin{array}{l}\text { 10. My milk is sufficient for my baby's intake. } \\
\text { 11. I have no problem feeding my baby because I have good nutrition. } \\
\text { 12. My breasts feel full when it is time to feed my baby. }\end{array}$ \\
\hline Baby's feeding capability and growth & $\begin{array}{l}\text { 13. My baby latches on my breast and sucks well. } \\
\text { 14. My baby sucks milk with a regular rhythm and swallows it. } \\
\text { 15. My baby's skin is plump and elastic. } \\
\text { 16. My baby is getting weight well. }\end{array}$ \\
\hline Being familiar with one's baby & $\begin{array}{l}\text { 17. I can catch what my baby wants. } \\
\text { 18. I carefully observe the baby's behavior to know what the baby wants. } \\
\text { 19. My baby is satisfied after breastfeeding. } \\
\text { 20. My baby does not cry during or after breastfeeding. }\end{array}$ \\
\hline Discomfort in breastfeeding & $\begin{array}{l}\text { 21. There are wounds in my nipples. } \\
\text { 22. Continuous pain in my nipples occurs while breastfeeding. } \\
\text { 23. I am tired or exhausted after breastfeeding. }\end{array}$ \\
\hline Maintenance of breast milk volume & $\begin{array}{l}\text { 24. I try to get enough rest and sleep for breastfeeding. } \\
25 . \text { I try to eat enough food and water for breastfeeding. }\end{array}$ \\
\hline Getting support & $\begin{array}{l}\text { 26. I can rest because I have someone to take care of housework or my babies. } \\
\text { 27. I have someone around me that makes me feel at ease. }\end{array}$ \\
\hline
\end{tabular}

